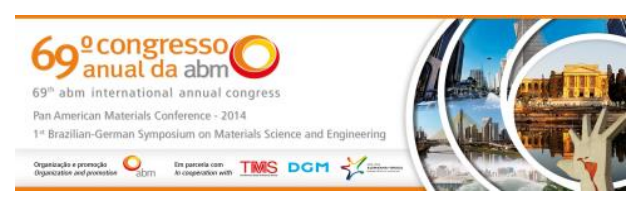

Tema: Metalurgia do Pó

\title{
COMPORTAMENTO DA ADIÇÃO DO CARBETO DE TÂNTALO - TaC NA MATRIZ METÁLICA DO AÇO EUROFER $97^{*}$
}

\author{
Leiliane Alves de Oliveira² \\ Uílame Umbelino Gomes ${ }^{3}$ \\ Calson Pereira Souza 4 \\ Murillo Menna Barreto de Mello Junior ${ }^{5}$ \\ Sérgio Renato da Silva Soares 6
}

\section{Resumo}

O aço EUROFER $(9 \mathrm{Cr}-1 \mathrm{~W})$, pode ser utilizado em turbinas para geração de energia, vasos de pressão, reatores nuclear ou aplicações, onde o material é submetido a temperaturas de serviço entre $250^{\circ} \mathrm{C}$ e $450^{\circ} \mathrm{C}$. Uma forma de melhorar as propriedades do aço, para que ele trabalhe a temperaturas mais altas ou que se torne mais estável é adicionar partículas de segunda fase na sua matriz. Estas partículas podem estar na forma de óxidos, carbetos, nitretos ou até mesmo em solução sólida quando alguns elementos químicos são adicionados ao material. Neste contexto, este trabalho objetiva estudar o efeito da adição de $3 \%$ de carbeto de tântalo na matriz metálica do aço ferrítico/martensítico. Para isto a metalurgia do pó foi a rota empregada para a produção deste compósito de matriz metálica (CMM). Duas moagens distintas foram realizadas. A primeira com o aço EUROFER e a segunda com o aço EUROFER com adição de $3 \%$ de carbeto de tântalo $(\mathrm{TaC})$. A moagem de alta energia foi realizada durante 5 horas. Em seguida, os dois pós produzidos foram sinterizados em um forno a vácuo (104torr) a temperatura de $1.250^{\circ} \mathrm{C}$ durante 60 minutos. O produto final foi caracterizado por microscopia óptica, microscopia eletrônica de varredura (EDS) e ensaio de microdureza. Os estudos iniciais dos sinterizados obteve uma resposta positiva nas propriedades mecânicas independente do processamento. Com valores de microdureza maior que $100 \%$ do valor de 333,2 HV obtidos para o aço puro como recebido(barra).

Palavras-chave: EUROFER 97; TaC; Metalurgia do pó; CMM.

\section{BEHAVIOR OF THE ADDITION OF TANTALUM CARBIDE - TaC MATRIX IN METALLIC STEEL EUROFER 97}

\begin{abstract}
The steel EUROFER $(9 \mathrm{Cr}-1 \mathrm{~W})$ may be used for power generation turbines, pressure vessels, nuclear reactors or applications where the material is subjected to temperatures of between $250^{\circ} \mathrm{C}$ and $450^{\circ} \mathrm{C}$. One way to improve the properties of the steel, so that it works at higher or become more stable temperature is to add second phase particles in the matrix. These particles can be in the form of oxides, carbides, nitrides and even some solid solution where chemicals are added to the material. In this context, this work aims to study the effect of adding 3\% tantalum carbide metal matrix in the ferritic / martensitic steel. To this powder metallurgy route was used for the production of metal matrix composite (CMM). Two different grinds were performed. As with the first and second EUROFER steel with steel EUROFER with addition of $3 \%$ tantalum carbide $(\mathrm{TaC})$. The high energy milling was performed for 5 hours. Then, the two powders produced were sintered in a vacuum furnace $\left(10^{-4}\right.$ torr $)$ at temperature of $1,250^{\circ} \mathrm{C}$ for 60 minutes. The final product was characterized by optical microscopy, scanning electron microscopy (EDS), and microhardness testing. Initial studies of sintering achieved a positive response in the mechanical properties of independent processing. With values greater than $100 \%$ of the value of 333.2 HV obtained for the pure steel as received (bar) microhardness.
\end{abstract}

Keywords: EUROFER97; TaC; Powder metallurgy; MMC.

1 Engenheira de Materiais. Aluna de doutorado. Universidade Federal do Rio Grande do Norte - UFRN. Natal, RN, Brasil.

2 Graduado em física Sócio da ABM. Dr. Professor Associado. Departamento de Física. UFRN. Natal, RN, Brasil. 3 Graduado em Engenharia química Dr. Professor. Departamento da Química. UFRN. Natal, RN, Brasil.

4 Graduado em engenharia elétrica Mestre. Técnico do Laboratório de Materiais Cerâmicos e Metais Especiais. UFRN. Natal, RN, Brasil.

5 Graduado em Engenharia Mecânica, Dr. Professor. Adjunto III. Universidade Federal do Mato Grosso - UFMT. Rondonópolis, MT, Brasil.

* Contribuição técnica ao 69ํ Congresso Anual da ABM - Internacional e ao 14ํ ENEMET - Encontro Nacional de Estudantes de Engenharia Metalúrgica, de Materiais e de Minas, 21 a 25 de julho de 2014, São Paulo, SP, Brasil. 


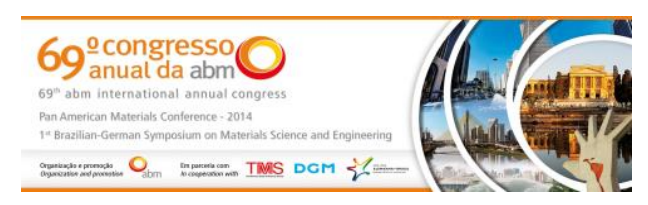

\section{INTRODUÇÃO}

Estudos mostram que os aços podem ter suas propriedades melhoradas com a adição de partículas de óxidos ou carbetos dispersos na matriz metálica [1-4]. Dentre estas propriedades podemos citar a resistência mecânica, onde o reforço com partículas dispersas na matriz pode aumentar a temperatura de trabalho do aço, pois este reforço atua como um mecanismo que impede o movimento das discordâncias que, por consequência, observa-se uma melhora na resistência a fluência, evita a propagação de trincas e aumenta a resistência à fadiga $[5,6]$. Segundo Klueh e colaboradores, temperaturas de trabalho de aproximadamente $700^{\circ} \mathrm{C}$ são alcançadas quando partículas de óxido dispersas na matriz metálica do aço são produzidas por metalurgia do pó e tratamentos termomecânicos.

A metalurgia do pó ( $P / M$ - Powder Metallurgy) é uma rota que pode ser utilizada para produção de componentes metálicos de ligas de aços reforçados com óxidos e carbetos para obtenção de peças com melhores propriedades e controle dimensional [9]. A metalurgia do pó é uma rota economicamente viável para o processamento de peças metálicas complexas com alta qualidade de acabamento e tolerância, quando comparadas com as técnicas convencionais (Gotoh, Masuda e Higashitani, 1997). Nos Compósitos de Matriz Metálica (CMM), um dos componentes geralmente age como matriz na qual o reforço se encontra disperso. Os reforços podem estar na forma de partículas, fios, fibras curtas ou fibras contínuas.

O Estado do Rio Grande do Norte é um grande produtor de minério de metais refratários $(\mathrm{W}, \mathrm{Ta}, \mathrm{Nb})$, minerais cerâmicos (diatomita, caulim, feldspato, mica, barita, argilas, etc) e outros minerais contendo terras raras e pedras semi-preciosas. Todavia essa riqueza natural do estado que o coloca entre os cinco maiores produtores de minerais do país não tem revertido em progresso e desenvolvimento para a região, principalmente devido à falta de agregação tecnológica a matéria-prima local.

Dados estatísticos mostram uma produção nos Estados Unidos de 473.804 toneladas de ferro e aço pela metalurgia do pó no ano de 2004. Estima-se que, devido ao custo, a produtividade e as propriedades requeridas que mais de $70 \%$ dos produtos são sinterizados por fase líquida para promover a densificação em baixas temperaturas [7]. Contudo o uso da fase líquida nem sempre traz um efeito positivo. A sua presença nas interfaces e contornos de grão melhora a densificação, mas também tem uma forte influência no mecanismo de deformação. Quando a sua qualidade aumenta, verifica-se a degradação de propriedades do material, como a dureza.

Dentro desse contexto pretende-se obter, através da técnica de Metalurgia do Pó (M/P) um novo material sinterizado a partir da moagem de alta energia do material particulado de aço inoxidável ferrítico/martensítico (EUROFER97) com carbetos de tântalo (TaCs).

O principal objetivo deste trabalho é o desenvolvimento e a caracterização de um novo material Compósito de Matriz Metálica - CMM capaz de obter uma dureza suficiente para aplicações especiais (Indústria nucleares), ferramentas de corte, etc. Para isso tem-se estudado qual a melhor rota de sinterização com o uso dos diferentes pós de $\mathrm{TaC}$, apresentando assim, um estudo sobre o desenvolvimento e a caracterização desse CMM, tendo como matriz um aço inox ferrítico/maretnsítico (EUROFER97) e contendo reforços de pós de carbetos de tântalo, com dimensões nanométricas, consolidado pela via da sinterização em fase sólida. Os carbetos foram escolhidos por serem estáveis, não reagindo com a matriz metálica, além de apresentarem alto ponto de fusão e alta dureza [8].

* Contribuição técnica ao 69 Congresso Anual da ABM - Internacional e ao 14 ENEMET - Encontro Nacional de Estudantes de Engenharia Metalúrgica, de Materiais e de Minas, 21 a 25 de julho de 2014, São Paulo, SP, Brasil. 


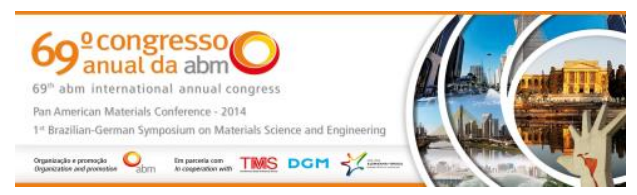

\section{MATERIAIS E MÉTODOS}

Como materiais de partida foram utilizados um bloco do aço EUROFER97(Fe, 0,11-C, 9-Cr, 1,1-W), fornecido pelo Instituto de Pesquisa em Energia Atômica (AEKI-KFKI Atomic Energy Research Institute) de Budapeste, Hungria, um pó sintetizado na UFRN de Carbeto de Tânatalo e um pó comercial de Carbeto de Tântalo fornecido por Sigma Aldrich. Para a caracterização inicial do aço, foram utilizadas as técnicas de microscopia ótica (MO) e microscopia eletrônica de varredura para observar a microestrutura. Para revelar a microestrutura foi usado o reagente Vilela a $2 \%$. Para avaliar as propriedades mecânicas, o ensaio de microdureza Vickers foi realizado utilizando um microdurômetro com carga de 100kgf durante 15 segundos.

A moagem do cavaco foi realizada num moinho de alta energia (MAE), com rotação de 400rpm por 5 horas. O fluído Ciclohexano foi usado como ambiente de moagem para evitar a oxidação dos pós, impedir a aderência do material às paredes do recipiente durante a moagem e melhorar a dispersão do pó na moagem. Primeiramente foi utilizado apenas o pó do aço EUROFER e depois foi adicionado $3 \%$ em peso de carbeto de tântalo (TaC UFRN/TaC comercial) ao aço ferrítico/martensítico.

Antes do processo de conformação dos pós, eles foram recozido no forno resistivo a vácuo numa temperatura de $950^{\circ} \mathrm{C}$ por 30 minutos com uma taxa de $10^{\circ} \mathrm{C} / \mathrm{min}$. No caso dos compósitos particulados com o TaC UFRN além do recozimento, foi necessário a adição de $2 \%$ de parafina para uma melhor compactação. Os materiais particulados foram compactados em matriz metálica cilíndrica de aço VC131 com diâmetro e altura de $5 \mathrm{~mm}$. A compactação foi feita por prensagem uniaxial com ação única do pistão superior. As medidas de carga aplicada à massa de pó em função do deslocamento do pistão foram realizadas numa prensa hidráulica. A pressão de compactação máxima aplicada foi de $600 \mathrm{MPa}$. Foram compactadas amostras de aço inox ferrítico/martensítico puro e amostras misturadas de aço com os diferentes carbetos.

Os experimentos de sinterização foram realizados num forno resistivo a vácuo da empresa Centor Vacuum Industries. As amostras compactadas foram sinterizadas a $1.250^{\circ} \mathrm{C}$ no tempo de 60 minutos sob vácuo $\leq 10^{-4}$ Torr. As amostras sinterizadas forma embutidas e polidas com pasta diamantada até uma granulometria $\cong 1 \mu \mathrm{m}$ para a realização das medidas de microdureza assim como para as análises de microscopia óptica e MEV, e ensaio de microdureza.

\section{RESULTADOS E DISCUSSÃO}

A Figura 1 mostra a microestrutura do aço inox EUROFER 97 como recebido em forma de barra, o qual possui uma microestrutura ferrítico/martensítico. Ele foi atacado com Vilela a $2 \%$ e com isso revelou sua microestrutura, na forma de ripas, característica típica de uma microestrutura com fase martensítica, e também com parte mais claras que pode ser identificada como fase ferrítica. $O$ resultado das medidas de microdureza encontrado nesse material foi de $333,2 \mathrm{HV}$.

* Contribuição técnica ao 69 Congresso Anual da ABM - Internacional e ao 14ํ ENEMET - Encontro Nacional de Estudantes de Engenharia Metalúrgica, de Materiais e de Minas, 21 a 25 de julho de 2014 , São Paulo, SP, Brasil. 

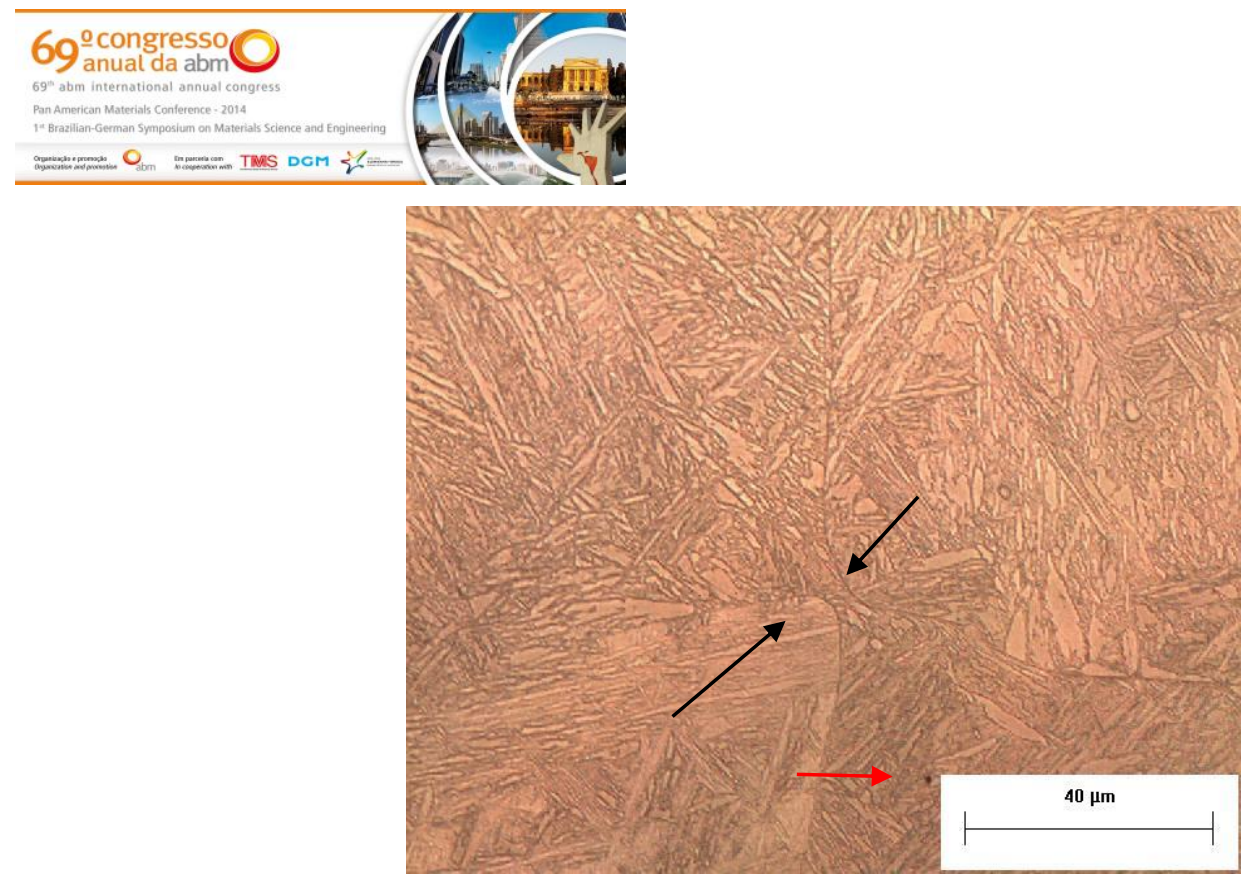

Figura 1: Micrografia MO (500x) da barra do aço EUROFER como recebido, atacada com Vilela a 2\%.

As Figuras 2 e 3 apresentam a micrografias (MO e MEV) dos sinterizados na temperatura de $1250^{\circ} \mathrm{C}$ em tempo de 60 minutos. Observando as micrografias (MO) dos sinterizados de aço puro (Figura 2a), sinterizado de aço com TaC UFRN (Figura 2b) e sinterizado de aço com TaC comercial (Figura 2c). É observada a porosidade que trata-se de poros pequenos e bem arredondados que indica o estágio final de sinterização. Os modelos idealizados de sinterização feitos por vários autores são específicos para cada estágio. Como o modelo de crescimento de grão para o $1^{\circ}$ estágio, o modelo da contração dos pós para os estágios intermediário e final e 0 modelo da contração dos poros para o estágio final [10]. Na Figura 3a observa-se na micrografia da amostra sinterizada de aço Eurofer puro os tamanho dos contornos de grão e a presença de duas fases, ferríta (parte mais clara) e a martensítica (parte mais escura). Comparada com a Figura 1, observa-se uma diminuição da fase martensítica, no caso da amostra que passou pelo processo de sinterização. Na Figura $2 b$ tem-se o sinterizado ETU, ainda com a presença de muitos poros, porém poros em formas segmentadas nas partículas e também em forma arrendondas o que indica uma sinterização em estágio saindo do intermediário e seguindo para o estágio final. Observa-se uma microestrutura com fases difusas, partes claras e escuras. Na Figura 2c tem-se uma amostra densificada, com contornos de grão com formas e tamanhos regulares e pequeno, porém, com a presença de uma fase única, bem característica de uma fase ferrítica, o que pode influenciar nas propriedades mecânicas do material.
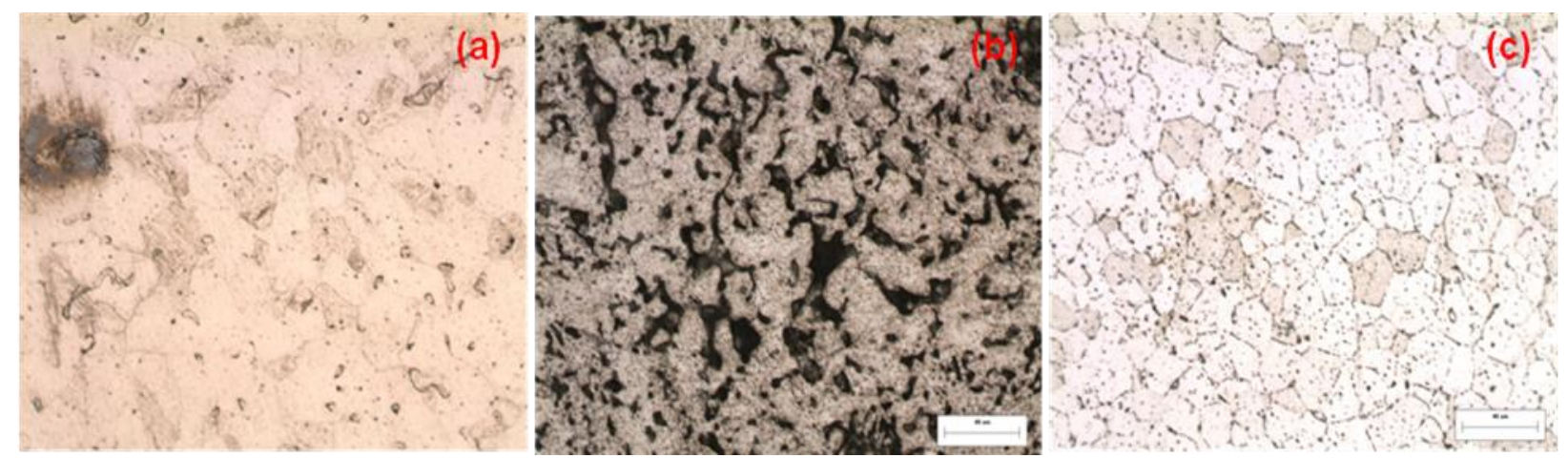

Figura 2. Micrografias (MO - 500x) dos sinterizado a $1250^{\circ} \mathrm{C}$ por 60 minutos; (a) Eurofer Puro(EP), (b) Eurofer com TaC UFRN(ETU) e (c) Eurofer com TaC comercial(ETC).

* Contribuição técnica ao 69ํ Congresso Anual da ABM - Internacional e ao 14ํㅡㄹ ENEMET - Encontro Nacional de Estudantes de Engenharia Metalúrgica, de Materiais e de Minas, 21 a 25 de julho de 2014, São Paulo, SP, Brasil. 


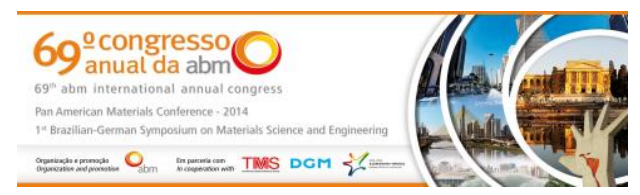

$\mathrm{Na}$ figura 3 estão presentes as imagens do MEV das amostras sinterizadas a $1250^{\circ} \mathrm{C} / 60 \mathrm{~min}$, nas quais também se observa a presença de poros, mas pode-se ver a distribuição das partículas de TaC na matriz metálica no caso das amostras da Figura 3b e 3c. Tem-se uma dispersão dos carbetos (parte branca) na matriz metálica do aço (parte cinza). Na Figura 3a tem-se o sinterizado de aço Eurofer puro com uma microestrutura que indica está no estágio final, pois os poros são pequenos e arredondados, típicos desse estágio. No caso do sinterizado do aço com TaC UFRN, estão dispersos na região em volta dos poros, o que pode ter dificultado o fechamento dos mesmo, assim como a não densificação da amostra, Figura 3b. Já no sinterizado de aço com TaC comercial, este estão dispersos de forma aleatória na matriz metálica e também em alguns contornos de grão, como pode-se observa na Figura 3c.

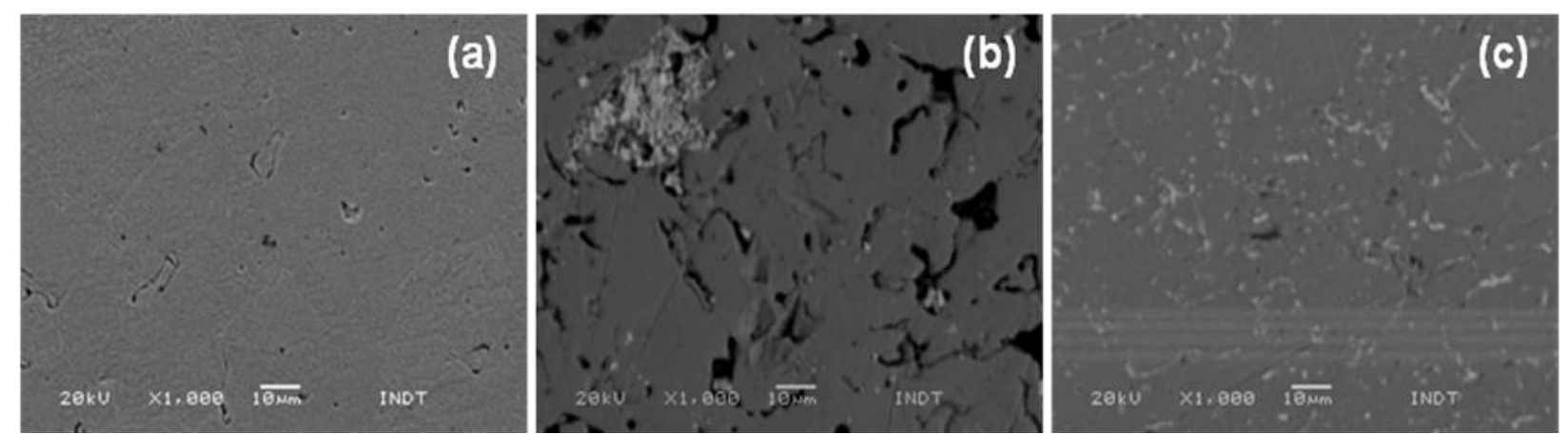

Figura 3. Micrografias (MEV - 1000x) dos sinterizado a $1250^{\circ} \mathrm{C}$ por 60 minutos; (a) Eurofer Puro(EP), (b) Eurofer com TaC UFRN(ETU) e (c) Eurofer com TaC comercial(ETC).

Na tabela 1 são apresentados os resultados de micro-dureza obtidos para amostras de Eurofer 97 puro, e com TaCs, sinterizadas na temperatura de $1250^{\circ} \mathrm{C}$ e tempo de $60 \mathrm{~min}$. Como pode ser visto, os valores das microdurezas variam de $302 \mathrm{HV}$ à $700,6 \mathrm{HV}$ este resultado está coerente com a maior temperatura de sinterização que é de $1250^{\circ} \mathrm{C}$, no caso da amostra ETU (Eurofer com TaC UFRN sinterizado a $1250^{\circ} \mathrm{C}$ por $60 \mathrm{~min}$ ). Isso pode esta relacionado também a mudança de fase que pode está ocorrendo devido a variação do tempo e da temperatura de sinterização das amostras de uma forma geral.

Observa-se que a amostra ETU obteve o valor de dureza mais elevada em relação a todas outras amostras, isso está relacionado com o tamanho da partícula bastante fino, descrito no procedimento experimental, e também com os parâmetros de sinterização dessa amostra, que foi sinterizada a $1250^{\circ} \mathrm{C}$ por 60 minutos. Mesmo não se tratando de uma amostra bem densificada.

Pode-se observar ainda na Tabela 1 a imensa diferença dos valores de microdureza entre a amostra de aço puro e de aço com o TaC UFRN em relação a amostra do aço com o TaC comercial, isso pode está associadas à dispersão de partículas grossas e/ou finas na matriz metálica, e isso se deve ao processo de síntese dos carbetos, o da UFRN mesmo com baixo aporte de energia, produziu partículas com tamanhos cristalito pequenos e mais homogêneo, em relação ao fornecido pela Aldrich, ou ainda pode está relacionado aos parâmetros de sinterização, ou pode está relacionado a transformação de fase, tipo, no sinterizado com o TaC comecercil a fase que prevalece é a ferríta, que possui baixa dureza, enquanto que nos sinterizados com o TaC UFRN tem a presença de outras fases, ou seja, o compósito continua ferrítico/martensítico como o aço inicial, além da presença das partículas, finas, dispersas ou embutidas na matriz metálica do aço Eurofer.

* Contribuição técnica ao 69ํ Congresso Anual da ABM - Internacional e ao 14º ENEMET - Encontro Nacional de Estudantes de Engenharia Metalúrgica, de Materiais e de Minas, 21 a 25 de julho de 2014 , São Paulo, SP, Brasil. 


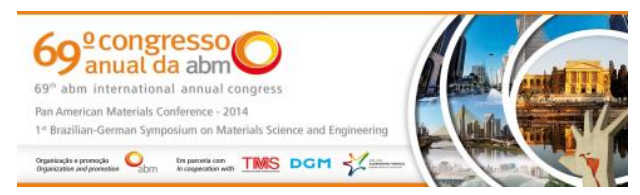

Tabela 2. Resultados da microdureza dos compósitos moídos por 5 horas, sinterizados na temperatura de $1250^{\circ} \mathrm{C}$ por 60 minutos.

\begin{tabular}{|c|c|c|}
\hline & Amostras & Microdurezas (HV) \\
\hline & EP & $636,8 \pm 35,6$ \\
\hline & ETU & $700,6 \pm 17,0$ \\
\hline & ETC & $191,2 \pm 8,0$ \\
\hline
\end{tabular}

\section{CONCLUSÃo}

As condições de moagem adotada resultam significativamente na compactação dos particulados, já que trata-se de partículas de tamanho densificados, pois isso facilita o preenchimento dos poros durante o processo de compactação.

Para os compósitos particulados de aço Eurofer 97 puro e com adição de 3\% de TaCs, 5 horas de moagem foi suficiente para uma boa homogeneidade dos compósitos particulados, mesmo no caso do aço de partida estar em forma de barra, e ainda obteve uma boa dispersão dos cabertos na matriz metálica.

Para as amostras sinterizadas de aço puro, houve um aumento no tamanho de grão, já no caso das amostras com a adição do TaC os grãoS reduziram de tamanho ou se mantiveram estáveis.

Houve uma diferença considerável nos resultados da microdureza dos compósitos reforçados com TaC UFRN e com o TaC fornecido pela Aldrich, sendo este com o menor valor de microdureza, menor até mesmo do que o sinterizado de aço puro, isso pode está relacionado com a variação na mudança de fases dos sinterizados, além dos diferentes TaCs utilizado, por se tratar de partículas finas/grossas respectivamente.

\section{Agradecimentos}

Ao CNPQ, a Capes, ao PPgCEM e a UFRN.

\section{REFERÊNCIAS}

1 Lucon E, Leenaers A, Vandermeulen W. Mechanical response of oxide dispersion strengthened (ODS) EUROFER97 after neutron irradiation at $300^{\circ} \mathrm{C}$. Fusion Engineering and Design, 2007;82:2438-2443.

2 Cayron C, et al. Microstructural evolution of Y2O3 and MgAl2O4 ODS EUROFER steels during their elaboration by mechanical milling and hot isostatic pressing. Journal of Nuclear Materials. 2004;335:83-102.

3 Furukava M. Sinterização de aço inoxidável reforçado com partículas nanométricas dispersas de carbeto de nióbio - NbC [Tese Doutorado em Ciência e Engenharia dos Materiais]. Natal: Centro de Tecnologia, Departamento de Engenharia dos Materiais, Universidade Federal do Rio Grande do Norte; 2007.

4 Oliveira LA. Estudo da Sinterização do Aço Inox 316L reforçado com 3\% de Carbeto de Tântalo - TaC [Dissertação de Mestrado em Engenharia e Ciência dos Materiais]. Natal: UFRN; 2008.

5 Castro V, et al. Mechanical dispersion of Y2O3 nanoparticles in steel EUROFER97: process and optimization. Journal of Nuclear Materials. 2003;322:228-234.

6 Castro V, et al. Mechanical and microstructural behaviour of Y2O3 ODS EUROFER97. Journal of Nuclear Materials. 2007;367-370:196-201.

* Contribuição técnica ao 69 Congresso Anual da ABM - Internacional e ao 14ํ ENEMET - Encontro Nacional de Estudantes de Engenharia Metalúrgica, de Materiais e de Minas, 21 a 25 de julho de 2014, São Paulo, SP, Brasil. 
7 ASM Handbook. Powder Metal Technologies and Applications. Volume 7. Editor(s): W.B. Eisen WB, Ferguson BL, German RM, lacocca R, Lee PW, Madan D, Moyer K, Sanderow $\mathrm{H}$, Trudel Y; 1998.

8 Souza CP, Medeiros FFP, Gomes UU. Obtenção De Carbeto De Tantalo Nanoestruturado A Baixa Temperatura A Partir De Precursor Oxalato (Nh4)3[Tao(C2o4)3].1,5h2o Através De Reação Gás-Solido. 2005.

9 Gomes UU. Tecnologia dos Pós - Fundamentos e Aplicações. Natal: UFRN Editora Universitária; 1995.

10 Thümmler F, Oberacker R. An Introduction to Powder Metallurgy. The Institute of Materials; 1993. 